Case Report

\title{
"Taurodontism" an endodontic challenge: a case report
}

\author{
Ramesh Bharti, Anil Chandra, Aseem P. Tikku and Kulvindar K. Wadhwani \\ Department of Conservative Dentistry and Endodontics, CSM Medical University, Lucknow, India
}

(Received 5 November 2008 and accepted 1 May 2009)

\begin{abstract}
Taurodontism can be defined as a change in tooth shape caused by the failure of the Hertwig's epithelial sheath diaphragm to invaginate at the proper horizontal level. An enlarged pulp chamber, apical displacement of the pulpal floor, and no constriction at the level of the cementoenamel junction are the characteristic features. Permanent molars are most commonly affected. Endodontic treatment of a taurodont tooth is challenging and requires special handling because of the proximity and apical displacement of the roots. Here, we report a case in which endodontic treatment of the maxillary right first molar with taurodontism was performed. In this case, the maxillary right second molar and maxillary left first and second molars were also taurodont teeth. ( $\mathrm{J}$ Oral Sci 51, 471-474, 2009)
\end{abstract}

Keywords: taurodontism; pulp chamber; endodontic treatment; maxillary molar.

\section{Introduction}

Taurodontism is a developmental disturbance of a tooth that lacks constriction at the level of the cementoenamel junction (CEJ) and is characterized by vertically elongated pulp chambers, apical displacement of the pulpal floor and bifurcation or trifurcations of the roots (1).

The term "taurodontism" ('bull tooth') was coined from the Latin term "tauros", which means 'bull' and the Greek term "odus", which means 'tooth'(2).

Shaw (1928) further classified taurodont teeth according

Correspondence to Dr. Ramesh Bharti, Flat no. 805, Doctors Flats, TG Hostel Campus, Khadra, Sitapur Road, Lucknow 226003, India

Tel: +91-9935724723

Fax: +91-522-2254555

E-mail: r_bharti14@yahoo.com to their severity into hypo-, meso- and hypertaurodont forms, hypotaurodontism being the least pronounced form, mesotaurodontism the moderate form and hypertaurodontism being the most severe form in which the bifurcation or trifurcation occurs near the root apices (3).

The etiology of taurodontism is unclear. The possible causes of taurodontism have been enumerated by Mangion (4) as follows: 1) A specialized or retrograde character, 2) A primitive pattern, 3) A Mendelian recessive trait, 4) An atavistic feature, and 5) A mutation resulting from odontoblastic deficiency during dentinogenesis of the roots.

According to Hamner et al., taurodontism is caused by the failure of Hertwig's epithelial sheath diaphragm to invaginate at the proper horizontal level (5). In addition, it has been reported that many patients with the Klinefelter syndrome exhibit taurodontism, but it is not a constant feature of this syndrome (6). Today, it is considered as an anatomic variant that could occur in a normal population (7). The prevalence of taurodontism is reported to range from $2.5 \%$ to $11.3 \%$ of the human population. This range is accounted for by variations in race and differences in diagnostic criteria (8). The present article describes the review of literature of taurodontism (Table 1) and management of hypertaurodontism by endodontic treatment in a right maxillary first molar.

\section{Case Report}

A 22-year-old male patient was referred to the postgraduate clinic of the Department of Conservative Dentistry and Endodontics, C.S.M. Medical University Lucknow, India for treatment of the maxillary right first molar. The tooth had been subjected to emergency pulpotomy by a general dentist because of irreversible pulpitis. The patient's medical history was noncontributory. At the time of examination, the tooth was asymptomatic. Intraoral examination revealed a normal shaped crown with a 
Table 1 Review of literature

\begin{tabular}{|c|c|c|}
\hline NO. & Author (s) & Work done \\
\hline 1. & Keith A (1913) & Use the term Taurodontism \\
\hline 2. & Shaw JC (1928) & $\begin{array}{l}\text { Named three sub-classes of taurodontism: Hypo, Meso and } \\
\text { Hypertaurodontism }\end{array}$ \\
\hline 3. & Kallay J (1963) & $\begin{array}{l}\text { Described a single rooted, wedge shaped molar that occurred in } \\
\text { association with taurodont teeth }\end{array}$ \\
\hline 4. & $\begin{array}{l}\text { Witkop et al. (1969), } \\
\text { Crawford JI (1970), } \\
\text { Parker JL et al. (1975), } \\
\text { Gage JP (1978), } \\
\text { Congletion et al. (1979) }\end{array}$ & $\begin{array}{l}\text { Taurodontism has been found to occur either as an isolated, single } \\
\text { trait or in association with syndromes and anomolies incuding } \\
\text { amelogenesis imperfecta }\end{array}$ \\
\hline 5. & Jasper MT (1981) & Taurodontism in Down's Syndrome \\
\hline 6. & $\begin{array}{l}\text { Levin LS et al. (1975), } \\
\text { Stenvik et al. (1972), } \\
\text { Jasper MT and Witkop CJ (1980) }\end{array}$ & Taurodontism in ectodermal disturbances \\
\hline 7. & $\begin{array}{l}\text { Yeh and Hsu (1998), } \\
\text { Keeler C (1973) }\end{array}$ & Taurodontism is associated with Klinfelter's syndrome \\
\hline 8. & $\begin{array}{l}\text { Mednick GA (1973), } \\
\text { Stewart RE (1974) }\end{array}$ & Taurodontism is associated with Mohr syndrome \\
\hline 9. & Fuks AB et al. (1982) & Taurodontism is associated with Osteoporosis \\
\hline 10 . & $\begin{array}{l}\text { Jorgenson RJ and Warson RW (1973), } \\
\text { Lichtenstein J et al. (1972), } \\
\text { Gulman's et al. (1976) }\end{array}$ & Taurodontism is associated with Tricho-dento-osseos syndrome \\
\hline 11. & $\begin{array}{l}\text { Meena (1971), } \\
\text { Barker (1976) }\end{array}$ & Genetic study of taurodontism \\
\hline 12. & Keene (1966) & $\begin{array}{l}\text { Taurodont index (it is related to the height of the pulp chamber to } \\
\text { the length of the longest root) }\end{array}$ \\
\hline 13. & Tulensalo et al. (1989) & $\begin{array}{l}\text { Had given simple method of assessing taurodontism using } \\
\text { orthopantomograms }\end{array}$ \\
\hline 14. & Blumberg et al. (1971) & Biometric method to diagnose taurodontism \\
\hline
\end{tabular}

temporary occlusal restoration. The tooth was not sensitive to percussion. Radiographic examination of the affected tooth revealed an abnormal tooth anatomy.

The radiographic findings were:

- The pulp chamber extended beyond the cervical area reaching the furcation.

- Three short roots were seen at the furcation area in the apical third.

From these radiographic findings, the tooth was diagnosed to be a hypertaurodont (Fig. 1). Hypertaurodontism on the contralateral side was confirmed by radiograph (Fig. 2).

\section{Endodontic management of the maxillary right first molar}

The tooth was anaesthetized, the access was opened under rubber dam isolation and the access cavity was modified. The remaining pulp tissue was extirpated. The pulp was voluminous and to ensure complete removal, $2.5 \%$ sodium hypochlorite was initially used as an irrigant to soften the pulp. Once the pulp was extirpated, further irrigation was done with normal saline. The pulp chamber was huge and the floor of the chamber could not be visualized. At the furcation area, three canal orifices were found: palatal, mesiobuccal and distobuccal. A working length radiograph was taken with a \#15 file in the canal and it was confirmed by an electronic apex locator (Root ZX; Morita, Japan) (9). 
After working length determination, the palatal canal was instrumented up to \# 40 file and the buccal canals up to \#30 file size. After completion of instrumentation, a modified obturation technique was used because of the proximity of the orifices. After drying the canals, AH plus (Dentsply International) sealer was applied onto the root canal walls with a lentulospiral (Dentsply /maillefer; Tulsa, OK, USA). The premeasured master cone was coated with sealer and slowly moved to full working length. Then, the premeasured \#30 spreader was introduced into the canal along side the master cone gutta percha and with a rotary vertical motion was slowly moved apically to full penetration. After a minute, the spreader was removed with the same reciprocating motion and immediately followed by the first \#30 accessory cone inserted to the full depth of the space left by the spreader then \#25 and \#20 accessory cones were inserted after the use of spreader. Thus, the canals were obturated with lateral condensation. After that, the elongated pulp chamber was obturated with vertical compaction of warm gutta percha. The final radiograph confirmed a well condensed filling of the canals (Fig. 3).

\section{Discussion}

A taurodont tooth shows wide variation in the size of the pulp chamber, varying degrees of obliteration and canal configuration, apically positioned canal orifices. Therefore, root canal treatment becomes a challenge $(10,11)$.

Taurodontism is a dental anomaly characterized by large pulp chambers and short roots. Roots often bifurcate or trifurcate at a low level. They are thought to result from failure of the Hertwig's epithelial root sheath to invaginate at the proper time (12). The most frequently affected teeth are the molars (7). The distance between the baseline connecting the two CEJ and the highest point in the floor of the pulp chamber are used in determining taurodont teeth. Taurodontism is diagnosed in molars when this distance exceeds $2.5 \mathrm{~mm}$ (7).

Taurodontism is associated with several developmental syndromes and anomalies including amelogenesis imperfecta, Down's syndrome, ectodermal disturbance, Klinefelter syndrome, tricho-dento-osseous syndrome, Mohr syndrome, Wolf-Hirschhorn syndrome and Lowe syndrome (8).

From an endodontist's view, taurodontism presents a challenge during negotiation, instrumentation and obturation in root canal therapy. The mesiobuccal and distobuccal canal orifices were very narrow and close to each other, due to which negotiation of these orifices was very difficult. During instrumentation, as the canals were

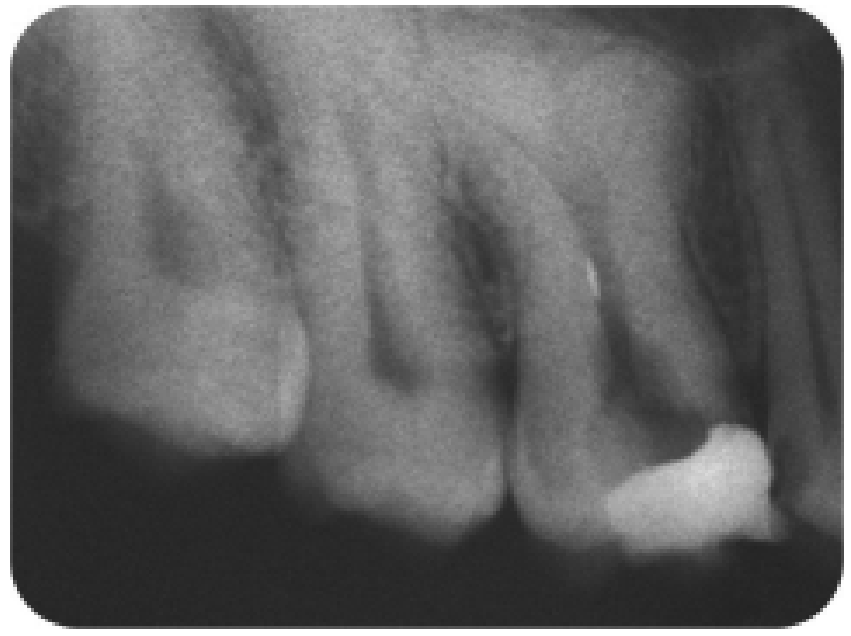

Fig. 1 Pre-operative radiograph of maxillary right first molar.

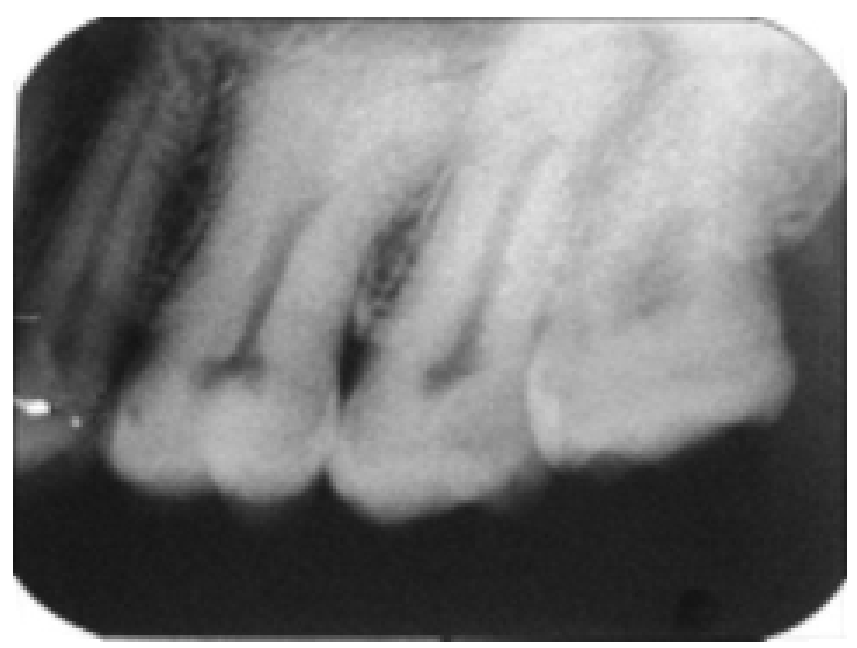

Fig. 2 Radiograph of contra lateral maxillary left first molar.

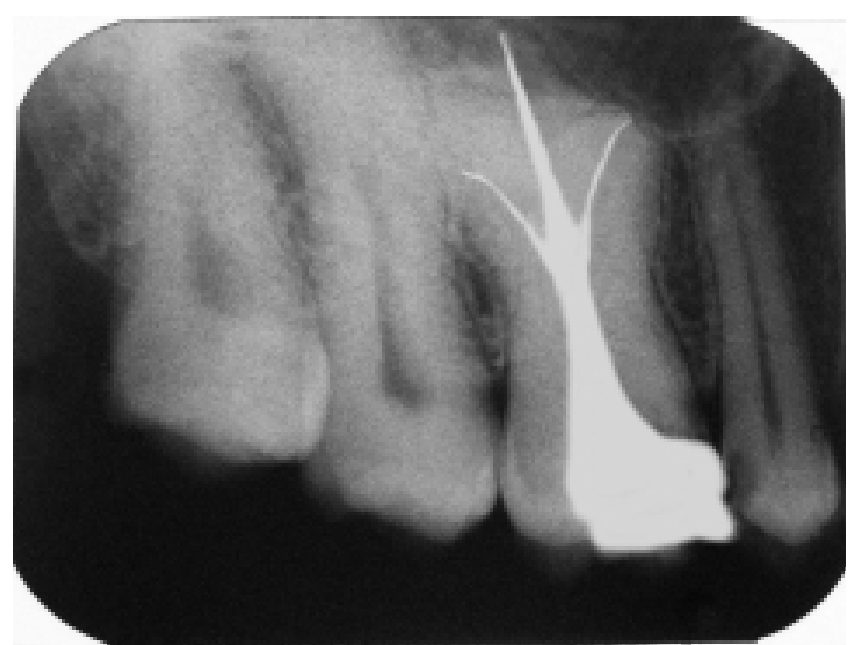

Fig. 3 Radiograph upon completion of root canal filling. 
very short, they were instrumented with only the apical third of the file. Therefore, instrumentation was timeconsuming. Similarly, due to the typical internal anatomy, where buccal canals were narrow and orifices were close, the canal orifices were also deeply placed in the tooth. Therefore, the obturation procedure was also different from the conventional one. The proximity of the orifices and deeply situated opening of the canals made it difficult to obturate the canals with any single method of obturation. Therefore, a combination of lateral condensation technique and warm vertical condensation technique was performed to achieve the best results and it can be seen in the post operative radiograph (Fig. 3).

Because of the complexity of the root canal anatomy and proximity of buccal orifices, complete filling of the root canal system in taurodont teeth is challenging. A modified filling technique, which consists of combined lateral compaction in the apical region with vertical compaction of the elongated pulp chamber, has been proposed (10).

Another endodontic challenge related to taurodont teeth is intentional replantation. The extraction of a taurodont tooth is usually complicated because of the dilation of the roots in the apical third (13). In contrast, it is also believed that because of its large body, little surface area of a taurodont tooth is embedded in the alveolus. This feature would make extraction less difficult as long as the roots are not widely divergent (14).

In addition to the difficulty of the endodontic procedure, the present case might suggest the possibility that taurodont teeth have an extraordinary root canal system which is challenging for endodontists.

\section{Acknowledgments}

The authors would like to thank Dr. Mala Kamboj, Reader (Career Institute of Dental Sciences, Lucknow) for her critical review and valuable suggestions.

\section{References}

1. Jafarzadeh H, Azarpazhooh A, Mayhall JT (2008) Taurodontism: a review of the condition and endodontic treatment challenges. Int Endod J 41, 375-388.
2. Keith A (1913) Problems relating to the teeth of the earlier forms of prehistoric man. J R Soc Med 6, 103124.

3. Shaw JC (1928) Taurodont teeth in South African races. J Anat 62, 476-498.

4. Mangion JJ (1962) Two cases of taurodontism in modern human jaws. Br Dent J 113, 309-312.

5. Hamner JE III, Witkop CJ Jr, Metro PS (1964) Taurodontism: report of a case. Oral Surg Oral Med Oral Pathol 18, 409-418.

6. Shafer WG, Hine MK, Levy MB (1999) A textbook of oral pathology. 4th ed, W. B. Saunders, Philadelphia, 43.

7. Shifman A, Chanannel I (1978) Prevalence of taurodontism found in radiographic dental examination of 1,200 young adult Israeli patients. Community Dent Oral Epidemiol 6, 200-203.

8. Joseph M (2008) Endodontic treatment in three taurodontic teeth associated with 48, XXXY Klinefilter syndrome: a review and case report. Oral Surg Oral Med Oral Pathol Oral Radiol Endod 105, 670-677.

9. Lucena-Martin C, Robles-Gijon V, Ferrer-Luque CM, Navajas-Rodriguez de Mondelo JM (2004) In vitro evaluation of the accuracy of three electronic apex locators. J Endod 30, 231-233.

10. Tsesis I, Shifman A, Kaufman AY (2003) Taurodontism: an endodontic challenge: report of a case. J Endod 29, 353-355.

11. Rao A, Arathi R (2006) Taurodontism of deciduous and permanent molars: report of two cases. J Indian Soc Pedod Prev Dent 24, 42-44.

12. Bhaskar SN (2001) Orban's oral histology and embryology. 11th ed, CV Mosby, St Louis, 41-44.

13. Yeh SC, Hsu TY (1999) Endodontic treatment of taurodontism with Klinefelter's syndrome: a case report. Oral Surg Oral Med Oral Pathol Oral Radiol Endod 88, 612-615.

14. Durr DP, Campos CA, Ayers CS (1980) Clinical significance of taurodontism. J Am Dent Assoc $100,378-381$ 